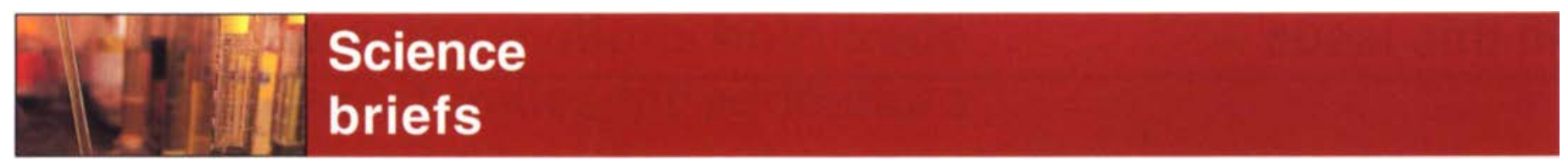

Estrogen-resistant strains of mice show normal sperm maturation following exposure to high $(40 \mu \mathrm{g})$ doses of estrogen. Note mature elongated spermatids (nearly mature sperm) in the center of this seminiferous tubule.
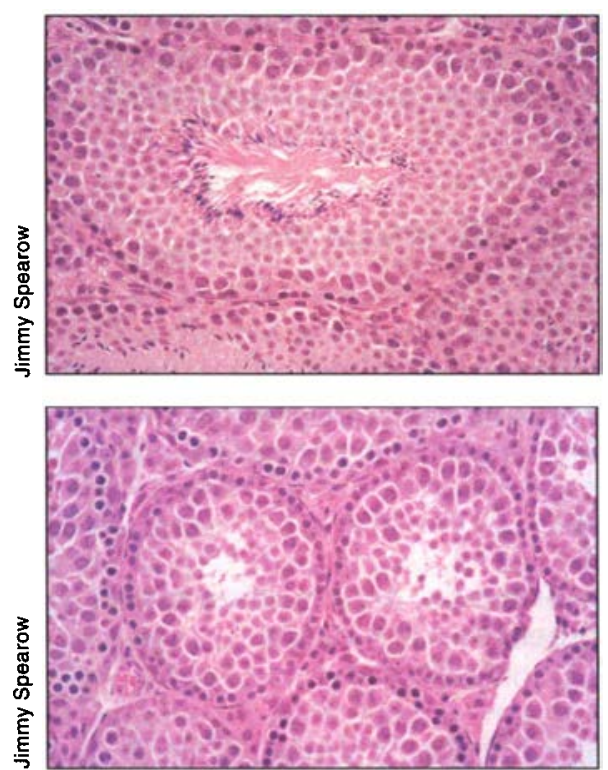

A Estrogen-sensitive strains of mice showed disruption of testicular development and sperm maturation by even the lowest doses of estrogen $(2.5 \mu \mathrm{g})$. Note the small, disrupted seminiferous tubules lacking elongated spermatids.

\section{Tahoe research partnership created}

A historic partnership has been reached among research institutions and local and federal agencies to advance research in the Lake Tahoe basin.

The new agreement is intended to help researchers and agencies work together to preserve and restore the Sierra Nevada crown jewel. While much is known about the increasing algal growth, declining clarity and influences of development on the lake's watershed, further coordinated scientific inquiry into such areas as watershed repair and air quality is vital, say agreement co-signers.

The memorandum of understanding between the Tahoe Regional Planning Agency and a host of federal agencies and research institutions will coordinate the collection and sharing of data.

Those signing the memorandum with the Tahoe Regional Planning Agency include UC Davis; U.S. Geological Survey; University of Nevada, Reno; Desert Research Institute; and the U.S. Forest Service Pacific Southwest Research Station.

\section{Variation in estrogen sensitivity may mask endocrine disruption}

Genetically different strains of laboratory mice vary dramatically in their sensitivity to estrogen, report UC Davis researchers in the Aug. 20 issue of the journal Science.

The findings by reproductive geneticist Jimmy Spearow and reproductive endocrinologist Marylynn Barkley call into question the validity of current laboratory-animal-based safety tests of estrogenlike chemicals and suggest that an individual's genetic makeup should be considered when prescribing estrogen and related hormones for medical purposes.

The U.S. Environmental Protection Agency is preparing to screen thousands of pesticides and industrial chemicals for several endocrinedisrupting effects. Previous studies have indi- cated that estrogenlike endocrine disruptors found in the environment can cause decreased sperm counts, deformed genitals, aberrant mating behavior and sterility in wildlife.

\section{Moms pass defensive vigor to offspring}

Mothers who have faced adversity produce kids who are physically better equipped to deal with the hardships of life, suggests a study by a UC Davis researcher.

Examining wild radish plants and the water flea Daphnia, ecologist Anurag Agrawal and colleagues found that defensive responses triggered in both species by their respective predators were passed on to the offspring, even though the young were not under attack.

Evidence of such "maternally induced" defenses is reported in the Sept. 2 issue of the journal Nature.

The findings may have implications for the ways in which insect pests are managed in crops grown for seed production, Agrawal noted. For example, seeds produced by plants that were heavily sprayed with pesticides to protect them against insects may not be as hardy as seeds produced by plants that endured some level of insect attack.

"We've generally believed that if plants are being hammered by insect pests they won't produce as healthy seeds as would undamaged plants," Agrawal said. "But the results of this study seem to indicate the opposite to be true."

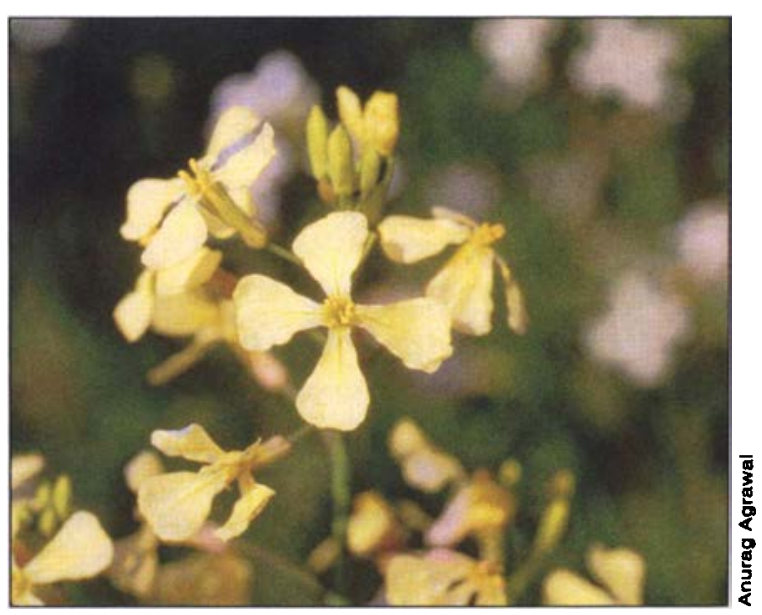

The offspring of caterpiliar-attacked wild radish plants had defensive chemicals, which deterred caterpillars from feeding on them. 